\title{
Pseudo Corporate Social Responsibility and Governance Mechanism
}

\author{
Yongmei Xu, Ying Liu \\ Jinan University, Guangzhou, China \\ Email: liuyingxxi@126.com
}

Received 23 February 2016; accepted 3 April 2016; published 7 April 2016

Copyright (C) 2016 by authors and Scientific Research Publishing Inc.

This work is licensed under the Creative Commons Attribution International License (CC BY). http://creativecommons.org/licenses/by/4.0/

c) (i) Open Access

\begin{abstract}
More and more enterprises are revealed to do something about pseudo social responsibility under the guise of social responsibility; it makes the rationality of the existence of experience of social responsibility a crisis of confidence. However, this phenomenon has not obtained the academic attention, and related studies are particularly scarce. On the basis of summarizing and combing existing literature, we defined pseudo corporate social responsibility, summarized the motivation of pseudo social responsibility in economic interests, the external environment, and the risk of exposed punishment, and described the harm of pseudo social responsibility from the micro and macro levels. Finally, we tried to put forward relevant policies to prevent pseudo social responsibility.
\end{abstract}

\section{Keywords}

Pseudo Social Responsibility, Motivation, Governance

\section{Introduction}

The enterprise always regards steady and rapid economic growth as their constant pursuit of goals. However, with the rapid economic growth, it has appeared a series of environmental and social issues. These social and environmental issues aroused the concern of the community, some organizations and scholars have emphasized the development of enterprises cannot blindly pursue the maximization of economic benefits, they must also take environmental and social issues into account, the thought of corporate social responsibility has been proposed. In other words, while enterprises achieve economic benefits, they should also take up social responsibility. In recent years, the degree of public attention to corporate social responsibility increased rather than decreased. Enterprises have realized the importance of social responsibility, they take corporate social responsibility into the enterprise development strategy, try to fulfill their social responsibility while achieving economic 
benefits, and realize a win-win of the enterprise and society. It would have been a very good sign, but unfortunately, some enterprises talk the talk, but did not walk the walk, and attempt in the name of social responsibility deceiving the public and doing pseudo socially responsible behavior for their own personal fame and fortune. But even more unfortunately, this phenomenon of a social responsibility show is spreading worldwide, the enterprise advertises their social responsibility on the one hand, but they are constantly being exposed out against the social responsibility of mass media events on the other hand. Which makes rationality and legitimacy of the existence of corporate social responsibility is being questioned, and suffers an unprecedented crisis of confidence, repels the enthusiasm of corporate social responsibility actions, and poses a serious challenge for sustainable economic development.

Currently, however, the pseudo-social responsibility has not given adequate attention in academia, the research of pseudo socially responsible behavior is still in its infancy, lack of relevant research results and theoretical support, so it is difficult to effectively solve the problem of the enterprise pseudo socially responsible behavior. If left unchecked, it will seriously affect the sustainable economic development in the long run. In this case, it is particularly urgent to reveal the true face of pseudo corporate social responsibility, make a distinction between pseudo corporate social responsibility and the real corporate social responsibility, consolidate the rationality of corporate social responsibility exist, and re-establish public trust in corporate social responsibility. Therefore, from the start of the definition of pseudo corporate socially responsible behavior, we stripped out the pseudo corporate social responsibility from the real social responsibility, analyzed the motivation and hazards of pseudo corporate social responsibility, and finally tried to make constructive policy for the management of the pseudo corporate social responsibility issues.

\section{Concept Definition}

Now pseudo corporate social responsibility has not yet clearly defined in academic, few studies have elaborated and studied on the "hypocrisy" in early days. The so-called hypocrisy, Wagner et al. [1] interpreted hypocrisy as enterprises promote itself different from the authentic self. Zhao Zhongjiang and In Minghe [2] thought that corporate social responsibility reflects a new social norms and values. From a perspective on social responsibility, Fan Shuai et al. [3] interpreted hypocritical behavior of enterprises as: Although the company itself said to be a socially responsible organization, but in its practical action did not really fulfill its social responsibility, but hoped to win for themselves a good reputation to get some kind of benefit. Cheng Yanrong and Hu Huan [4] thought explaining the corporate hypocritical behavior by difference "words" and "deeds" is too thin from the starting point of engaging in corporate philanthropy. Wang Jingfeng, Zhou Weizhong [5] argued that the pseudo socially responsible behavior is a commitment to the public on the surface or an action seems to fulfill the social responsibility, but its essence, is based on profit maximization as the goal. Xiao Hongjun et al. [6] described pseudo social responsibility from the broad and narrow respectively. They thought, broadly, pseudo corporate social responsibility was not out of true motivation for socially responsible, and exhibited socially responsible behavior on the surface or "socially responsible" result of the process on the motivation level, or on the level of words and deeds separation, corporated statement even encourage others to be responsible for the society in public, but privately it did not take even against the social responsibility action. But in the narrow sense, pseudo social responsibility refers to the definition from the words and deeds of the separation level. And Zhao Hongdan [7] was trying to analyze the motives of pseudo socially responsible behavior. Mou Yupeng et al. [8] investigated the reasons for corporate philanthropy strategy backfired from the perspective of consumer perception.

By collating and summarizing the literature, we found that most of them the defined pseudo social responsibility derived from its decomposition, pseudo Social responsibility is a new term by the "pseudo" and "social responsibility" formed by the combination. But "pseudo" means fake, pose, false; "social responsibility" means a socially responsible behavior of a corporate-companies should take on all aspects of employees, communities, the environment, consumers and other social responsibilities in the pursuit of economic objectives, Thus, the pseudo social responsibility can be understood as a false or posing socially responsible behavior, that is to say companies do not practice what they preach, only use social responsibility as their umbrella to escape social responsibility activities, or exaggerate its existing social responsibility activities in avoiding public condemnation, while obtaining a profit.

Pseudo corporate social responsibility activities are often hidden in the corporate social responsibility activities, and the public gets information within the enterprise is limited, therefore, it can potentially be difficult 
identify and strip out pseudo social responsibility activities from the behavior of corporate social responsibility. There are essential differences from the original motivation, behavior, communication and performance between pseudo social responsibility activities and real social responsibility activities. From the perspective of the original motivation, real social responsibility activities are to achieve the enterprise's economic goals, but also to create value for society as a whole, the initial motivation is to benefit society; while pseudo social responsibility activities merely look on their own profit, completely ignoring the social value added or not, they are entirely profit-driven. From the perspective of the behavior, real social responsibility activities are on behalf of companies will do their best to take appropriate action to ensure socially responsible, incorporate social responsibility into their own business development strategy, implement the various sectors of corporate social responsibility actions earnestly; while pseudo-social responsibility activities do not take social responsibility behavior, or do against the social responsibility behavior. From the perspective of the communication, real social responsibility activities require companies to disclose their own impact on the community and other relevant information objectively and fairly, transparently, impartially and properly communicated; while pseudo-social responsibility activities are often "self-proclaimed", "puff", "glossy", exaggerated or even conceal distort the truth in order to mislead the public. From the perspective of the performance, real social responsibility activities will be coordinated their own development and social development, the performance is not to maximize the performance of individual companies but the whole society, although self-interest companies caused may be not obvious in short-term, but in the long term, it must achieve maximum benefits; while pseudo-social responsibility activities are often focusing on their short-term financial performance, ignoring social morality even contrary to law, it may achieve improved financial performance in short-term, but it will jeopardize their own development and even the whole society over time.

\section{Motivation and Harmfulness}

\subsection{Motivation}

The occurrence of pseudo corporate socially responsible behavior is not accidental, enterprise would assess the consequences arising from the decision before doing the decision of pseudo-social responsibility activities. Simply is, enterprises would analyze the consequences respectively of doing pseudo socially responsible behavior or not. If companies do not pseudo socially responsible behavior, enterprises will contrary to sustainable development social expected, and will be questioned inevitably by all walks of life, corporate image damaged their own economic interests will be harmed, at the same time, other companies benefit from socially responsible behavior, but companies themselves did not get the same in return, relatively speaking, it is also considered a "loss". And if companies do pseudo socially responsible behavior, such fraud revealed a very small chance of being disclosed, because of limited access for external to get information within the enterprise, even if lies were revealed, it is difficult to be subject to appropriate legal penalties in accordance with existing laws, and the cost is small relatively. Analysis of motivation of enterprise pseudo social responsibility activities from four aspects: economic interests, external environment, the risk of exposure and punishment.

1) Economic interests. The enterprise is the very nature to achieve maximum benefits. To constant pursuit of their own economic interests are the key inherent factors of pseudo social responsibility activities. Point of view from the cost-benefit, When enterprises do pseudo social responsibility activities, they just give the public a verbal promise, pretend to make some irrelevant, ambiguous strategy, execute symbolically or simply do not perform, they do not need to inject a lot of financial and human resources. While pseudo-social responsibility activities was able to bring the benefits as real social responsibility activities can enhance the corporate image, it brings short-term benefits almost reach the same level. Under this measure, the choice of pseudo social responsibility activities is a rational man choice; the fundamental drive is the pursuit of economic interests.

2) External environment. With the concept of sustainable development has been widely accepted, value orientation of all sectors of society have also undergone a new change, the public requirement for the enterprise is not just on the economy, they began to demand more social corporate responsibility. Social responsibility is also increasingly becoming an important factor in the decision-making of investors and consumers, Forced by this pressure, companies have to adapt to this trend, Initiative to meet the public's value orientation to gain more resources and markets using pseudo social responsibility activities. On the other hand, corporates perceived pseudo socially responsible behavior did not get punished but may have some benefits by other companies, while they would miss their benefits without pseudo socially responsible behavior, this kind of psychological as 
an important factor also encourage enterprises to carry out pseudo socially responsible behavior

3) The risk of exposure. Because there is a serious information asymmetry, the outside world is difficult to obtain information within the enterprise, coupled with the current academic study of pseudo social responsibility activities is not sufficient, defining and measuring of pseudo social responsibility activities are vaguer. It makes the pseudo socially responsible behavior has such characteristics like secrecy, ambiguity, complexity, and the outside world is difficult to identify socially responsible. At the same, the lack of related laws and regulations of pseudo-social responsibility which allows the risk of exposure pseudo socially responsible behavior is minimal. Although in reality, pseudo socially responsible behavior of some enterprises was exposed out, Such as "Southern Weekly" published "Annual green washing List” from 2010 onwards, a number of well-known domestic and foreign companies were on the list, but they are still only a tiny fraction of phenomenon of pseudo social responsibility, the vast majority of enterprises of pseudo social responsibility are still lurking around us.

4) Punishment. As the vacancies of existing laws and regulations in pseudo social responsibility, and the relevant system are not perfect, the punishment on pseudo corporate social responsibility behavior is insufficient through legal means. And general public also has the "forgetfulness", even if the behaviors of pseudo social responsibility was discovered, the punishment is often extremely light or even impunity, And the limited power and the short-time of public opinion does not constitute a deterrent effect, which makes companies do not fear of the risk of being brought to light of their pseudo socially responsible behavior.

\subsection{Harmfulness}

As an important part of society, pseudo socially responsible behaviors of enterprises have a profound impact on not only itself, but also on society. It is essential to investigate possible hazards of pseudo socially responsible behavior in the micro and macro levels

1) First, pseudo corporate social responsibility behavior will erode the competitiveness of enterprises. Companies claim that they were fulfilled their social responsibilities, it makes the public enterprises have a higher expectation positioning on them, While pseudo-social responsible behavior as an opportunistic behavior, will give the public a psychological gap, make a negative evaluation on companies once discovered, moreover, the public might no longer trust companies, and then questioned the quality of products, financial, tax and other aspects, companies will run out of trouble. In the existing legal system, the possibility of pseudo social responsibility behavior came to light is relatively small, but in the long run, the pseudo socially responsible behavior came to light is inevitable, by that time ,Sanctimonious mask of company cracked, corporate image instantly collapsed, and even into a crisis of confidence. In the short term, the pseudo socially responsible behavior will bring a certain amount of resources and markets, however, if the enterprise has been under the aegis of the pseudo-business socially responsible behavior and difficult to get rid of their dependence, it can cause them be more difficult to adapt to the trend of large social sustainable development, competitiveness will be eroded away.

At the same time, pseudo socially responsible behavior will make the companies truly fulfill their social responsibility lose power. The current market there are still serious information asymmetry, the public is difficult to distinguish who is really to fulfill their social responsibility, who is "posturing" pseudo-social responsibility when companies are put on the cloak of social responsibility, although consumers have a preference for social responsibility, but can only make consumer choices by price comparison, But the real social responsibility companies is bound to make the investment in the process of fulfilling social responsibility, its price relative lack of competitive advantage, and gradually been eliminated. Thus, the real corporate social responsibility will lose the motivation to continue to fulfill their social responsibilities.

2) Macro levels

Pseudo socially responsible behavior will make rationality of the existence of social responsibility has been questioned. With pseudo socially responsible behaviors are increasingly being exposed, the public questioned the social responsibility, they even suspect social responsibility is simply a means of business marketing, is nonexistent, public awareness of social responsibility will misunderstand or even distorted over time, it will have a serious threat on the healthy development of social responsibility.

More terrible is that, pseudo socially responsible behavior could lead to the stagnation or even retrogression of sustainable development. Pseudo socially responsible behavior would push back a portion of the real social responsibility of companies, cut their passion for social responsibility, and real social responsibility is gradually 
replacing by the pseudo-social responsibility. Without corporates truly fulfill social responsibility, we do not even talk about sustainable development.

\section{Governance Mechanism}

The most effective method to control pseudo companies social responsibility behavior is to start with the motivation of pseudo socially responsible behavior. Targeted to weaken motivation, pseudo socially responsible behavior might convert to real social responsibility behavior.

1) Controlling the pseudo socially responsible behavior fundamentally requires companies change their ideas to "social brokers" from the traditional "brokers", understanding profit maximization is no longer the ultimate goal of most companies, in this process, enterprise managers play a decisive role in the wizard. Correctly understanding the relationship between enterprise and society, and fully understanding concept of social responsibility, repositioning position of company in society, Facing up requirements and expectations of community on the company, undertaking a variety of social responsibility initiatively, and incorporating social performance evaluation into enterprise performance evaluation system. Moreover, companies should construct pseudo socially responsible behavior early warning system, correct corporate behavior deviation timely.

2) Only the concept of transition of managers is still not enough to govern pseudo socially responsible behavior, companies also need to improve the moral quality of all personnel, strengthen self-discipline, not just parroting the crowd, timely self-reflection. Enterprises should try to create a positive organizational culture, promote concept of corporate culture of integrity, pragmatic style of work. Managers timely guide and constraints on employees, and ultimately the formation of full participation, mutual help enterprises ethical climate, and then Eliminate possibilities of Rationalizing and blindly follow.

3) In the process of governance pseudo social responsibility behavior, supervision of the mass media is an important part. Just rely corporate self-restraint has a strong subjective, high uncertainty on the issue of pseudo socially responsible behavior, therefore, we need external public supervise the enterprise behavior. For now, it potentially difficult to expose pseudo corporate social responsibility behavior, but there has been part of the mass media step ahead devoted to uncovering pseudo social responsibility behavior. Mass media is a good supervision has more abundant resources than the masses, and they can spread out pseudo social responsibility information better. When the mass media reports pseudo social responsibility behavior, they must have been obtained conclusive evidence in advance and stated facts without emotionally rendering, handed over relevant information to authorities, and tracked reports.

4) Speeding up the Legislation process work of pseudo social responsibility behavior is also an important step. Carving out of bounds of pseudo social responsibility or not, and measuring pseudo socially responsible behavior and appropriate punishment clearly eliminate companies trusting to luck, adhere to the concept of "Once discovered, it will be severely punished". The Government should also improve relevant systems as soon as possible, assessment and disclosure fulfillment of corporate social responsibility, convey to the masses positive and correct concept of social responsibility to enhance the universal sense of social responsibility.

\section{Summary and Outlook}

Currently, studies on concept, motivation and other factors of pseudo social responsibility have made certain achievements, but because pseudo social responsibility has just started, the researchers have not yet set foot in many fields of study. Since the current theoretical system is incomplete, research area is not wide and development time is not long, there are still some shortcomings and deficiencies in pseudo social responsibility research, research topics and areas are relatively scattered and not systematic. Future research is still necessary to further the structure of the pseudo social responsibility, carrying out multi-level and interdisciplinary research as much as possible with the multifaceted power, and determining the secondary factors of pseudo social responsibility and the relationship between the various factors. While paying attention to the universality and scope research, furthering study needs to enhance the depth of research at the same time, this will be an important direction for future research.

\section{References}

[1] Wagner, T., Lutz, R.J. and Weitz B.A. (2009) Corporate Hypocrisy: Overcoming the Threat of Inconsistent Corporate Social Responsibility Perceptions. Journal of Marketing, 73, 77- 91. http://dx.doi.org/10.1509/jmkg.73.6.77 
[2] Zhao, Z.J. and In, M.H. (2008) Discussing Corporate Social Responsibility on Normative Nature of Whole Community. Journal of Shenyang Normal University (Social Science Edition), 3, 71-73.

[3] Fan, S., Tian, Z.L., Lin, J. and Wang, B.L. (2014) Review and Prospect of Companies Hypocrisy Based on Social Responsibility Perspective. Foreign Economics \& Management, 36, 2-12.

[4] Cheng, Y.R. and Hu, H. (2014) Companies Hypocrisy: Concepts, Hazard and Control Mechanism. Journal of North China Electric Power University (Social Sciences), 8, 43-46.

[5] Wang, J.F. and Zhou, W.Z. (2015) Definition and Transformation form of Pseudo Social Responsibility. Technoeconomics \& Management Research, No. 7, 57-61.

[6] Xiao, H.J., Zhang, J.S. and Li, W.Y. (2013) Study on pseudo Social Responsibility Behavior. China Industrial Economics, No. 6, 109-121.

[7] Zhao, H.D. (2014) Motivation of Pseudo Social Responsibility Behavior. Contemporary Finance \& Economics, No. 12, 77-86.

[8] Mou, Y.P., Wang, T. and Wang, B. (2012) Why Is Corporate Philanthropy Strategy Backfired? Luojia Management Review, No. 2, 56-57. 